\title{
Pengaruh Jarak Penembakan pada Pelapisan 95MXC Terhadap Sifat Kekerasan dan Keausan Material SS 304 dengan metode Twin Wire Arc Spray (TWAS)
}

\author{
Deni Fajar Fitriyana*, Gunawan Dwi Haryadi, Sulardjaka, Norman Iskandar, Abdi Gilang Amrizal \\ Departemen Teknik Mesin, Fakultas Teknik, Universitas Diponegoro \\ Jl. Prof. Sudharto, SH., Tembalang-Semarang 50275, Telp. +62247460059 \\ *E-mail: deniifa89@gmail.com
}

\begin{abstract}
The coating process on SS 304 with thermal spray method can be considered as a method for increasing wear resistance. In this study aims to determine the effect of spraying distance on the SS 304 coating process with the twin wire arc spray coating method on increasing wear resistance with 95MXC coating material. The range of spraying distances used was $100 \mathrm{~mm}, 200 \mathrm{~mm}, 300 \mathrm{~mm}$ and $400 \mathrm{~mm}$ with a air pressure 4 bar. From the results of the study, at $100 \mathrm{~mm}$ spraying distance produced hardness on coated of material $1227 \mathrm{HV}$, the value of wear rate was $4.0 \times 10^{-4} \mathrm{~mm}^{3} / \mathrm{s}$, percentage of porosity and unmelt $9.27 \%$ and strength of coating adhesion is $22.62 \mathrm{MPa}$. The shorter the spraying distance, will increase the hardness so that the value of the wear rate obtained decreases. This is because the percentage of porosity and unmelt is smaller.
\end{abstract}

Keywords: Twin Wire Arc Spray, SS 304, Hardness, Wear.

\section{Abstrak}

Proses pelapisan pada SS 304 dengan metode thermal spray dapat di pertimbangkan sebagai metode untuk peningkatan ketahan aus. Dalam penelitian ini bertujuan untuk mengetahui pengaruh jarak penembakan pada proses pelapisan SS 304 dengan metode twin wire arc spray coating terhadap peningkatan ketahanan aus dengan material coating 95MXC. Variasi jarak penembakan yang digunakan adalah $100 \mathrm{~mm}, 200 \mathrm{~mm}, 300 \mathrm{~mm}$ dan $400 \mathrm{~mm}$ dengan air pressure 4 bar. Dari hasil penelitian, pada jarak penembakan $100 \mathrm{~mm}$ menghasilkan nilai kekerasan $1227 \mathrm{HV}$, nilai laju keuasan $4,0 \times 10^{-4} \mathrm{~mm}^{3} / \mathrm{s}$, nilai presentase porositas dan unmelt 9,278\% dan kekuatan lekat coating sebesar 22,62 MPa. Semakin dekat jarak penembakan, nilai kekerasan yang dihasilkan akan semakin tinggi sehingga nilai laju keausan yang didapatkan menurun. Hal tersebut dikarenakan rendahnya nilai presentase porositas dan unmelt.

Kata Kunci: Twin Wire Arc Spray, SS 304, Kekerasan, Keausan.

\section{Pendahuluan}

Dalam merancang suatu komponen, kegagalan material sangat dihindari. Kegagalan material dapat menyebabkan ketidakpresisian ukuran yang lebih lanjut menyebabkan fungsi komponen tidak berjalan dengan baik. Salah satu kegagalan material adalah keausan atau wear. Keausan adalah hilangnya materi dari permukaan benda padat sebagai akibat dari gerakan mekanik [1]. Keausan dapat menyebabkan komponen profil berubah, performa kinerja komponen menurun, hingga pada akhirnya memperpendek umur kerja komponen [2]. Salah satu alternatif yang digunakan untuk mengatasi keausan adalah dengan mengganti komponen mesin. Namun hal tersebut terkendala bahan yang perlu diimpor sehingga waktu yang dibutuhkan menjadi cukup lama dengan biaya yang cukup besar pula.

Saat ini telah dikembangkan suatu metode untuk mengatasi keausan dengan menggunakan proses thermal spray coating. Metode ini tidak perlu mengganti seluruh mesin saat terjadi keausan, hanya perlu mengganti komponennya saja [2]. Prinsip dasar dari proses thermal spray adalah pembentukan lapisan permanen dengan meleburkan suatu material dalam suatu ruang pembakaran, kemudian dari ruang pembakaran ini material disemprotkan ke permukaan substrat dan kemudian menempelkannya di atas substrat [3]. Thermal spray coating merupakan metode pelapisan yang telah diterima dengan baik di kalangan industri. Hal tersebut dikarenakan kemudahannya untuk diaplikasikan pada pelapisan material dalam skala besar. Selain itu thermal spray coating merupakan teknologi yang ramah lingkungan. Metode thermal spray coating yang lazim digunakan yaitu High Velocity Oxygen Fuel (HVOF), Powder Oxy-Fuel Spraying dan Electrical Twin Wire Arc Spraying (TWAS). Proses pelapisan dengan metode TWAS dipilih dalam penelitian ini, karena biaya yang lebih murah, kemudahan dalam aplikasi, waktu aplikasi yang lebih cepat, serta kemudahan dalam proses perbaikan coating [4].

Oleh karena itu penelitian ini sangat diperlukan, karena pelapisan logam adalah suatu cara yang dilakukan untuk memberikan sifat mekanik dan ketahanan laju aus pada permukaan substrat, dimana substrat tersebut diharapkan mengalami perningkatan kekerasan dan ketahanan aus maupun perbaikan pada struktur mikro. 


\section{Material dan Metodologi}

Spesimen SS304 silinder dan plat dipotong menurut dimensi yang ditentukan sebanyak 8 buah. Melakukan proses abrasive grit blasting menggunakan alumunium oxide 24 mesh dengan tekanan sebesar 4 bar dan jarak penembakan 100 $\mathrm{mm}$. Hal ini bertujuan agar permukaan substrat menjadi kasar serta untuk meningkatkan ikatan mekanik antara material substrat dengan pelapisan. Sebelum melakukan proses coating terlebih dahulu melalukan spraying bond coat 75B (NiAl) dengan tekanan 4 bar dan jarak nozzle $100 \mathrm{~mm}$ [5]. Bond coat ini berfungsi sebagai lapisan perekat antara substrat dengan lapisan top coat. Selanjutnya melakukan spraying 95MXC, dengan variasi jarak yang digunakan 100 $\mathrm{mm}, 200 \mathrm{~mm}, 300 \mathrm{~mm}$ dan $400 \mathrm{~mm}$. Setelah dilakukan coating, dilakukan pengujian keras dengan metode microhardness vickers. Pengujian ini dilakukan untuk mengetahui nilai kekerasan pada permukaan dan 3 lapisan dengan kondisi sebelum dan setelah pelapisan. Pengujian ini menggunakan mesin microhardness vickers digital Standar pengujian menggunakan ASTM 92-82 tahun 2003. Pengujian Pin On Disk dilakukan dengan menggunakan alat pin on disk. Standar pengujian menggunakan ASTM G99-95A tahun 2000. Pengujian mikrografi untuk melihat hasil pelapisan yang ditunjukan pada penampang melintang dan tiga lapisan yaitu top coat, bond coat dan substrat. Standar pengujian menggunakan ASTM E3 tahun 2007. Proses SEM dilakukan untuk melihat hasil pelapisan yang ditunjukan pada penampang melintang. Scanning Electron Microscope (SEM) dengan merek Phenom ProX Desktop SEM. Pengujian pull off bonding dilakukan untuk mengetahui daya lekat coating terhadap substrat. Pengujian ini menggunakan lem araldite yang berfungsi sebagai perekat antara pin dengan spesimen yang akan diuji. Pengujian akan berhenti ketika lem sudah terlepas dari spesimen, dengan menarik sebagian permukaan coating. Pull off bonding ini menggunakan alat posiTest AT-M Adhesion Tester dengan standar ASTM D-4541. Nilai dari kelekatan akan ditunjukkan dari alat dalam satuan MPa.

\section{Hasil dan Pembahasan}

\subsection{Hasil Pengujian Kekerasan}

Pengujian kekerasan lapisan coating dengan menggunakan mikrohardness vickers tester (Model Mitutoyo HM-21) di lapisan permukaan dan di tiga lapisan coating top coating,bond coating dan substrat ditunjukan Gambar 1. Beban yang digunakan sebesar $500 \mathrm{gf}$ dengan lama indentasi $10 \mathrm{~s}$.

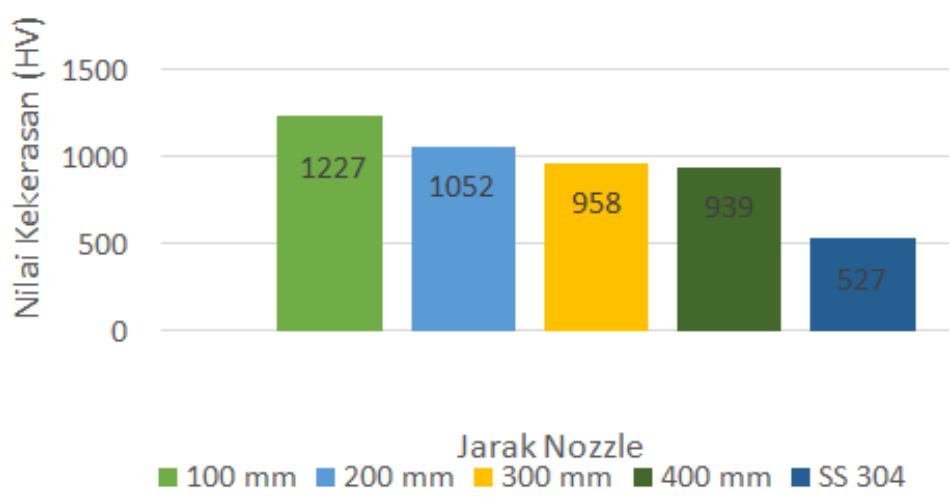

Gambar 1. Grafik Mikrohardness Vickers

Gambar 1 yang menunjukkan hasil uji kekerasan permukaan sebelum dan sesudah pelapisan, dimana substrat yang tidak dilapiskan memiliki kekerasan sebesar 527 HV sedangkan yang telah dilapisi memiliki kekerasan sebesar 9001250 HV. Perbedaan substrat sebelum dilapisi dengan substrat yang sudah dilapiskan memiliki nilai kekerasan yang cukup signifikan karena material pelapis memiliki kekerasan yang lebih tinggi daripada substrat material. Dari Gambar 3.1 telihat bahwa nilai kekerasan cenderung menurun dengan peningkatan jarak penembakan dari spray gun Twin Wire Arc Spray, hal ini disebabkan oleh meningkatnya nilai presentase porositas dan unmelt pada lapisan coating, selain itu marstensite yang terkandung di dalam lapisan di pengaruhi oleh jarak penembakan. Ukuran partikel yang dihasilkan juga semakin kecil sehingga struktur mikro pada pelapisan semakin padat dan homogen, hal ini juga dapat meningkatkan nilai kekerasan coating [6].

\subsection{Pengujian SEM}

Hasil pengujian Scanning Electron Microscope (SEM) ditunjukan pada Gambar 2. Pengujian ini dilakukan untuk mengetahui jumlah porositas dan unmelt yang terbentuk pada penampang melintang (cross section). 


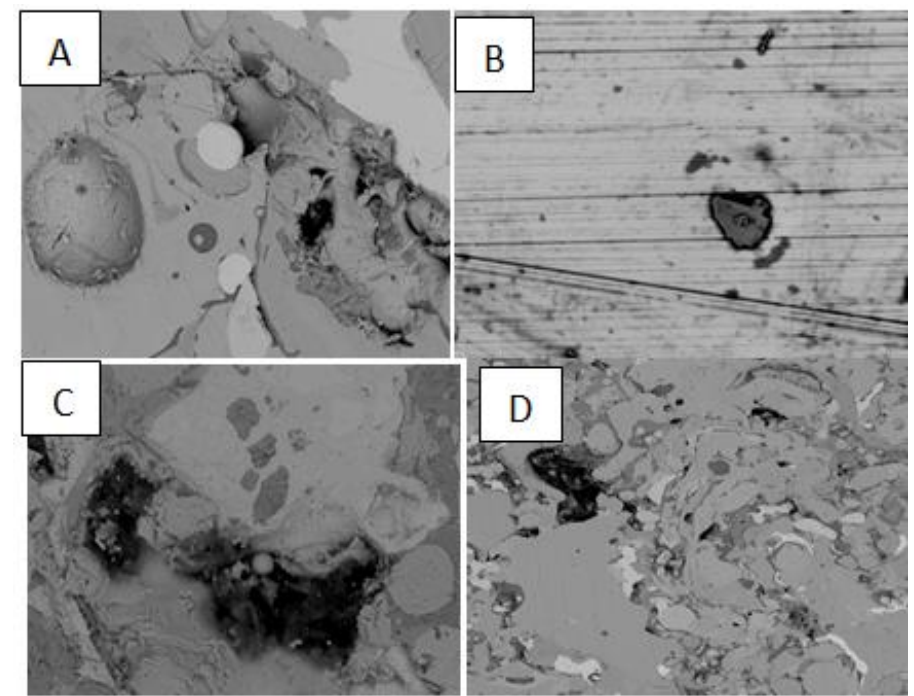

Gambar 2. Hasil SEM (A) 100 mm, (B) 200 mm, (C) 300 mm dan (D) $400 \mathrm{~mm}$

Analisa porositas dan unmelt pada bagian cross section menggunakan hasil pengujian Scanning Electron Microscope (SEM) dengan perbesaran 4000x yang ditunjukan pada Gambar 3.2 dengan menggunakan software image J. Hasil perhitungan porositas dan unmelt pada bagian cross section dengan image $J$ ditunjukan pada Gambar 3.3.

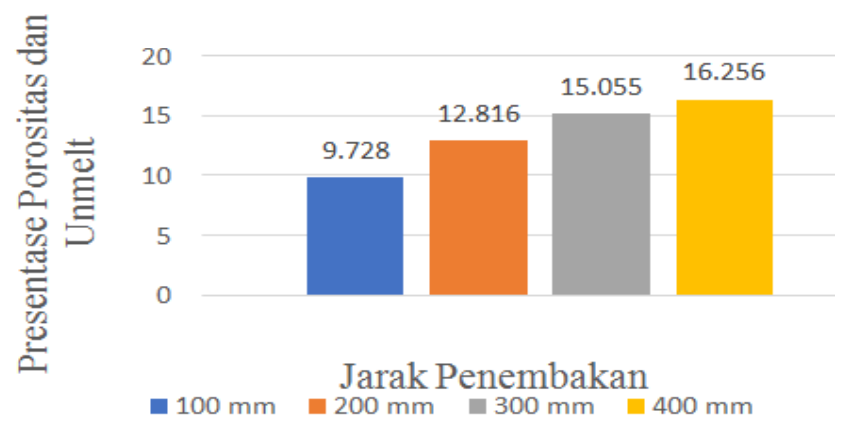

Gambar 3. Grafik Besaran Persentase Porositas dan Unmelt

Gambar 3 menunjukkan hasil perhitungan \% porositas dan \%unmelt setelah pelapisan dengan variasi jarak $100 \mathrm{~mm}$, $200 \mathrm{~mm}, 300 \mathrm{~mm}$ dan $400 \mathrm{~mm}$. Berdasarkan hasil pengukuran tersebut didapat nilai \% porositas dan \%unmelt pada substrat dengan jarak $100 \mathrm{~mm}, 200 \mathrm{~mm}, 300 \mathrm{~mm}$ dan $400 \mathrm{~mm}$ masing-masing sebesar 9,728\%; 12,816\%; 15,055\%; dan $16,256 \%$. Gambar 3.3 menunjukkan peningkatan \% porositas dan \%unmelt terhadap jarak penembakan dari $100 \mathrm{~mm}$ ke $400 \mathrm{~mm}$, hal inilah yang menyebabkan adanya penurunan nilai kekerasan terhadap peningkatan jarak penembakan dari spray gun [7].

\subsection{Hasil Pengujian Pin on disk}

Pengujian ini dilakukan untuk mengetahui nilai ketahanan aus pada material setelah dilakukan coating. Material diletakan menjadi pin dengan diberi beban 300 gram dan dilakukan proses abrasif menggunakan amplas yang menjadi disk dengan kecepatan $100 \mathrm{~m} / \mathrm{s}$. Pengujian ini dilakukan selama 10.000 putaran setiap 500 putarannya diganti dengan amplas yang baru. Pengujian ini dilakukan untuk mendapatkan Perhitungan laju keausan dimana dilakukan dengan mengukur berat yang hilang (weight loss) selama proses dan kemudian dikurangi dengan luas area yang tergerus pada substrat. Nilai hasil pengujian weight loss dan laju keausan dilihat Tabel 1.

Tabel 1. Pengujian Weight loss dan laju keasuan

\begin{tabular}{ccccccc}
\hline Spesimen & $\begin{array}{c}\text { Jarak Penembakan } \\
(\mathrm{mm})\end{array}$ & $\begin{array}{c}\text { Nilai kekerasan } \\
(\mathrm{HV})\end{array}$ & $\begin{array}{c}\text { Massa Awal } \\
(\mathrm{gram})\end{array}$ & $\begin{array}{c}\text { Massa Akhir } \\
(\mathrm{gram})\end{array}$ & $\begin{array}{c}\text { Weight Loss } \\
(\mathrm{gram})\end{array}$ & $\begin{array}{c}\text { Laju Keuasan } \\
(\mathrm{mm} / \mathrm{s})\end{array}$ \\
\hline $\begin{array}{c}\text { Sebelum } \\
\text { Pelapisan }\end{array}$ & - & 527,3 & 25,3046 & 19,3674 & $59 \times 10^{-1}$ & $2,0 \times 10^{-2}$ \\
\hline 1 & 100 & 1226,6 & 33,0694 & 33,0089 & $6,0 \times 10^{-2}$ & $4,0 \times 10^{-4}$ \\
2 & 200 & 1052 & 27,7585 & 27,6720 & $6,7 \times 10^{-2}$ & $4,6 \times 10^{-4}$ \\
3 & 300 & 958 & 28,5095 & 28,4416 & $8,6 \times 10^{-2}$ & $5,9 \times 10^{-4}$ \\
4 & 400 & 938,9 & 31,1411 & 31,0375 & $1,0 \times 10^{-1}$ & $6,8 \times 10^{-4}$ \\
\hline
\end{tabular}


Pada Tabel 1 dapat diketahui bahwa weight Loss dan laju keausan yang terjadi pada material yang tidak dilapisi lebih besar dibandingkan material yang dilapisi. Pada Tabel 3.1 juga menunjukan peningkatan weight loss dan laju keausan jika jarak penembakan diperbesar. Dari penelitian ini diketahui spesimen yang memiliki nilai kekerasan yang lebih tinggi mempunyai volume keausan yang rendah, sedangkan spesimen yang mempunyai nilai kekerasan yang rendah memiliki volume keausan yang tinggi [8]. artinya spesimen yang memiliki kekerasan yang tinggi memiliki ketahanan aus yang tinggi pula begitupun sebaliknya spesimen yang kekerasan rendah memiliki nilai ketahaanan aus yang rendah [9].

\subsection{Pengujian Pull Off Bonding}

Pengujian ini dilakukan untuk mengetahui daya lekat coating terhadap substrat. Pengujian ini menggunakan lem araldite yang berfungsi sebagai perekat antara pin dengan spesimen yang akan diuji. Pengujian akan berhenti ketika lem sudah terlepas dari spesimen, dengan menarik sebagian permukaan coating. Pull off bonding ini menggunakan alat posi Test AT-M Adhesion Tester dengan standar ASTM D-4541. Nilai daya lekat coating terhadap substrat ditunjukan pada Gambar 4.

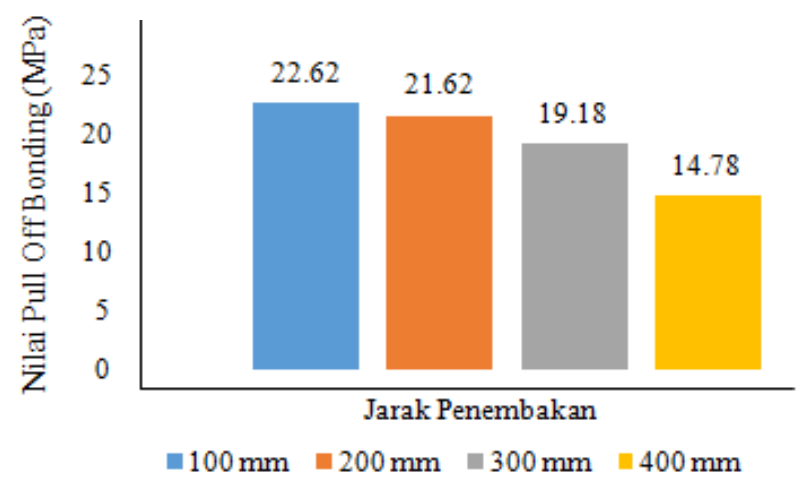

Gambar 4. Grafik Hasil Pull Off Bonding

Gambar 4 menunjukkan pengaruh jarak penembakan terhadap kekuatan adhesi coating. Berdasarkan gambar tersebut semakin jauh jarak penembakan menurunkan kekuatan daya lekat (adhesi) coating terhadap substrat. Pengaruh jarak penembakan menyebabkan menurunnya kekuatan daya lekat antara coating dengan substrat dan kohesi antar coating yang disebabkan adanya difusi 95MXC dari substrat ke coating dan 75B dari coating ke substrat [5]. Semakin jauh jarak penembakan akan meningkatkan \%porositas dan \%unmelt. Peningkatan \%porositas dan \%unmelt mengakibatkan penurunan daya lekat coating [10]. Hal ini sesuai dengan hasil uji SEM yang dianalisa menggunakan software imageJ didapat nilai \% porositas dan \%unmelt pada substrat dengan jarak $100 \mathrm{~mm}, 200 \mathrm{~mm}, 300 \mathrm{~mm}$ dan 400 mm masing-masing sebesar 9,728\%; 12,816\%; 15,055\%; dan 16,256\%.

\section{Kesimpulan}

Nilai kekerasan sebelum dilakukan pelapisan $527 \mathrm{HV}$, setelah dilakukan pelapisan dengan jarak $100 \mathrm{~mm}, 200 \mathrm{~mm}$, $300 \mathrm{~mm}$ dan $400 \mathrm{~mm}$ didapatkan masin-masing nilai kekerasan cross section $1227 \mathrm{HV}, 1052 \mathrm{HV}, 958 \mathrm{HV}$ dan 939 HV. Semakin jauh jarak penembakan, nilai kekerasan yang dihasilkan akan semakin kecil karena \% porositas dan \%unmelt semakin besar. Didapatkan hasil laju keausan pada SS304 sebelum pelapisan $2 \times 10^{-2} \mathrm{~mm}^{3} / \mathrm{s}$, setelah pelapisan pada material SS 304 jarak penembakan $100 \mathrm{~mm}, 200 \mathrm{~mm}, 300 \mathrm{~mm}$ dan $400 \mathrm{~mm}$ masing-masing memiliki nilai laju keausan $4 \times 10^{-4} \mathrm{~mm}^{3} / \mathrm{s} ; 4,6 \times 10^{-4} \mathrm{~mm}^{3} / \mathrm{s} ; 5,9 \times 10^{-4} \mathrm{~mm}^{3} / \mathrm{s}$; dan $6,8 \times 10^{-4} \mathrm{~mm}^{3} / \mathrm{s}$. Semakin jauh jarak penembakan nilai laju keausan semakin meningkat dan ketahan aus semakin menurun karena nilai kekerasan yang semakin kecil.

\section{Referensi}

[1] Rabinowicz, E., 1995, Friction and Wear of Materials, 2nd Edition. New York: John Wileyand Sons, INC.

[2] Pawlowski, L., 2008, The Science and Engineering of Thermal Spray Coatings Edisi Kedua, London: John Wiley \& Sons Ltd.

[3] Lusiani, R., Sunardi, Hamidi, 2013, Sifat Mekanik Lapisan Stainless Steel 316 pada Baja Karbon Rendah dengan Proses Electric Arc Spray, Seminar Nasional Industrial Services (SNIS) III, Cilegon 13 Oktober 2013.

[4] Fu Bin-you, 2009, Effect of heat treatment on the microstructure and mechanical properties of Fe-based amorphous coatings, A College of Materials Science and Engineering, Beijing University of Technology, Beijing 100124, China.

[5] Madaeni, S.S., Aalami, M.E., Daraei, P., 2008, Preparation and characterization of metallic membrane using wire arc spraying, Journal of membrane Science 320, pp. 541-548. 
[6] Sarikaya, O., 2005, Effect of the Substrate Temperature SS 304L On Properties of Plasma Sprayed A12O3 Coatings. Materials and Design. pp. 53-57.

[7] Tucker, Jr., 1994. Thermal Spray Coatings, Surf. Eng., Vol.5, ASM Handbook, P. 497-509.

[8] Veselin, B., 2010. "Slurry Pump Impeller Wear: Testing”. Journal of Tribology. Vol. 132.

[9] McCaul, C., Roger, K., 2004, Evaluation of Coating for Resistance to Abrasive and Adhesive Wear in Pump Components, Proceedings of the ninth international pump users symposium. New Jersey.

[10] Tillmann, W., Hagen, L., Luo, W., 2017, Process Parameter Settings and Their Effect on Residual Stresses in WC/W2C Reinforced Iron-Based Arc Sprayed Coatings, Coatings 2017, 7, 125. P.1-18. 